\title{
Auch HeldInnen haben (kranke) Beine
}

\section{Phlebologie für den sicheren Stand - Erfahrung, Evidenz, Innovation, Erfolg}

\section{Liebe Kolleginnen und Kollegen,}

herzlich willkommen zur 60. Jahrestagung der Deutschen Gesellschaft für Phlebologie in Bielefeld.

Die vergangenen Wochen und Monate waren anstrengend und aufregend schließlich bereitet man nicht jedes Jahr eine so große Tagung vor. Ich möchte mich bei allen Mitwirkenden und Organisatoren herzlich bedanken. Auch möchte ich mich herzlich für das Vertrauen der DGP bedanken, mich für 2018 mit der Aufgabe der Kongressorganisation betraut zu haben.

Wir freuen uns nun auf spannende Tage in Bielefeld mit vielen interessanten Sitzungen, Workshops und Symposien, besetzt mit hochkarätigen nationalen und internationalen Referenten. Besonders freue ich mich, dass wir auch in diesem Jahr wieder eine Vielzahl neuer Gesichter in den aktiven Rednerreihen begrüßen dürfen. Es sind nicht nur Phlebologen, sondern auch einige angrenzende Disziplinen vertreten.

Eine kleine Auswahl der Themen der Tagung 2018 in Bielefeld finden Sie in die- ser Kongressausgabe der Phlebologie, die jedoch nur einen Bruchteil dessen darstellt, was es an interessanten und abwechslungsreichen Themen auf der Jahrestagung in Bielefeld geben wird. Entsprechend der Vielseitigkeit der modernen Phlebologie finden sich Beiträge zur Epidemiologie, zur phlebologischen Versorgung, zur Valvuloplastie, zur Ulkustherapie und zur operativen Therapie.

Die Abstracts der Jahrestagung finden Sie wie in den letzten Jahren auch auf der Kongresshomepage: www.phlebologie-2018.de

Ich hoffe, Sie genießen diese Kongressausgabe und sie weckt Ihre Lust an der aktiven Teilnahme am Kongress in Bielefeld. Herzlich willkommen in Bielefeld und viel Vergnügen bei der Lektüre dieser Ausgabe der Phlebologie wünscht Ihnen

\section{Priv.-Doz. Dr. Helger Stege}

Kongresspräsident DGP 2018 und

Gastschriftleiter

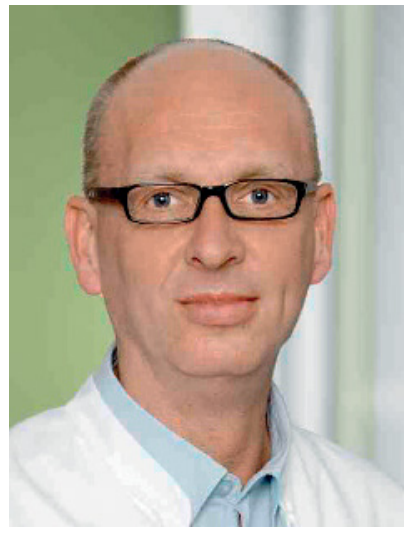

Priv.-Doz. Dr. Helger Stege, Detmold 